\title{
Portfólio de Matemática: uma evidência do processo de aprendizagem com apropriação tecnológica
}

\author{
Aline Silva De Bona \\ vivaexatas@yahoo.com.br \\ Marcus Vinicius de Azevedo Basso \\ mbasso@ufrgs.br \\ Instituto de Matemática - Programa de Pós-Graduação em Ensino de Matemática - \\ Universidade Federal do Rio Grande do Sul (UFRGS) \\ Porto Alegre - RS - Brasil
}

\section{Resumo}

O trabalho é parte dos resultados de uma pesquisa-ação desenvolvida em 2009 no PPGENSIMAT/UFRGS numa escola pública estadual em Porto Alegre, que tem por objetivo compreender o processo de aprendizagem do estudante em matemática. Com o decorrer do trabalho em sala de aula evidencia-se uma apropriação tecnológica natural pelos estudantes, tanto como estratégia e/ou forma de apresentação dos seus portfólios a professora, colegas, e a comunidade. Apresenta-se neste trabalho o trabalho construído e apresentado pelos estudantes do $3^{\circ}$ ano do Ensino Médio para a comunidade de acordo com a responsabilidade e autonomia de construção dos próprios estudantes e segundo o que julgavam necessário para que todos compreendessem o significado de portfólio de matemática, como forma de demonstrar o que aprenderam de matemática.

Palavras-chaves: Portfólio de Matemática. Processo de Aprendizagem. Responsabilidade e Tecnologias.

\begin{abstract}
The work is part of the results of a research program developed in 2009 PPGENSIMA/ UFRGS a public school in Porto Alegre, which aims to understand the process of student learning in mathematics. In the course of work in the classroom evidence is a natural technological appropriation by students, both as strategy and / or way of presenting their portfolios to teacher, classmates, and community. It read in this work only one they show the work constructed and presented by students of the 3rd year of high school to the community according to its responsibility and autonomy to build what they thought necessary for everyone to understand the meaning of portfolio mathematics as a way to demonstrate what they learned in mathematics, in his words.
\end{abstract}

Keywords: Portfólio of Mathematics. Learning Process. Responsibility and Technologies.

\section{Introdução}

A necessidade de despertar o interesse dos estudantes para a aula de matemática foi à motivação principal para esta mudança de prática educativa baseada no uso de portfólios de matemática. Ela vem sendo desenvolvida há mais de dez anos com o objetivo de compreender o processo de aprendizagem de cada estudante, respeitando sua realidade, conhecimento já adquirido e aspecto social, proporcionando para estes um espaço de aprendizagem; e compreendendo a avaliação como um componente da prática do professor assim como a constante necessidade de comunicação entre professor e estudantes, estudantes e estudante e todos com a escola, segundo uma linguagem viável, mas de significado aos estudantes sobre a matemática. Assim, é neste contexto que se insere as tecnologias digitais de informação e comunicação, ou seja, como uma estratégia de aprendizagem escolhida pelos estudantes. 
A proposta neste artigo é evidenciar apenas um exemplo do espaço de aprendizagem criado pelos estudantes, ou seja, a ação dos estudantes a partir de uma oportunidade dada aos mesmos de apresentar sua produção em matemática, num sábado letivo na escola, para toda a comunidade, segundo o trabalho desenvolvido sobre os portfólios de matemática.

\section{Varal de Matemática e Português: Portfólio de Matemática}

Em 2009, devido ao recesso da gripe H1N1 alguns sábados foram letivos para toda a Escola. Assim, foi proposta aos estudantes a criação de um Varal de Matemática e Português, junto com toda a escola. Essa atividade foi autorizada pela Secretaria de Educação e Cultura do Estado do RS e constituía em demonstrar para a comunidade o aprendizado de Matemática e/ou de Português através de qualquer instrumento, e que fosse aplicada a outras áreas do conhecimento ou isoladamente, ou seja, a proposta era "mostrar", em especial para os próprios pais, o que foi aprendido em Matemática, via apresentação de casos exemplares. Estavam disponíveis aos estudantes os espaços da escola, como corredores, salas de aula, murais e pátio. Ressalvamos que, como o único laboratório de informática é de uso comum para toda escola, para não haver injustiças na escolha de quem o utilizaria, este ficou fechado.

Salientamos que não se tratava de uma simples exposição porque o espaço de apresentação devera ser organizado pelos estudantes; a escolha do que produzir para esta apresentação não era um trabalho dado pelo professor, era da escolha de cada estudante, podendo inclusive ser individual ou em grupo e, como aspecto mais interessante, o trabalho deveria ser apresentado/falado aos visitantes, e não apenas exposto como um pôster. Essa estratégia tinha como objetivo despertar a autonomia do estudante frente ao seu processo de aprendizagem e criar um espaço para que eles desenvolvessem o que lhes interessava.

Foram muitos os trabalhos de qualidade desenvolvidos pelos estudantes de toda a escola, desde as séries finais do ensino fundamental até o último ano do ensino médio. A escola esteve cheia de visitantes, inclusive de outras escolas, de $9 \mathrm{~h}$ às $14 \mathrm{~h}$, em novembro de 2009. Cada turma dividiu-se em aproximadamente 3 grupos, sendo o total de turmas envolvidas foram 27 - manhã, tarde e noite -, dentre estas 8 desenvolvem o trabalho com os portfólios de matemática. Das 8 turmas, totalizando 25 trabalhos em grupo e 6 individuais, apenas 2 em grupo e um individual não utilizaram recursos tecnológicos para sua apresentação, e de 31 apenas um estudante não apresentou seu portfólio de matemática diretamente, pois ele fez um cartaz sobre os cuidados com a água, via pesquisa online. Tais dados fornecem evidências da apropriação tecnológica dos estudantes como uma contextualização e também interdisciplinaridade, bastando que o professor seja receptivo às ideias dos estudantes. Frisamos que esse é um dos focos do trabalho com portfólios de matemática. Salientamos ainda que a escola "fechou" o laboratório de informática, e mesmo assim os estudantes providenciaram computadores, os trouxeram para a escola, e realizaram suas apresentações como puderam. Na ausência de projetores multimídia, fizeram várias sessões de apresentação, em círculo, com pequenos grupos, pois deviam explicar o trabalho criado. Tal fato é resultado da pesquisa-ação na qual os estudantes envolvidos se tornam responsáveis pelo seu processo de aprendizagem de forma autônoma.

\section{Uma "evidência” sobre o Portfólio de Matemática}

As figuras a seguir são recortes de um vídeo produzido sobre os portfólios de matemática para o Varal de Matemática e Português pela turma do $3^{\circ}$ ano da manhã. $\mathrm{O}$ 
vídeo, cuja autorização para divulgação foi dada pelos estudantes e responsáveis, foi totalmente produzido pelos quatro estudantes.
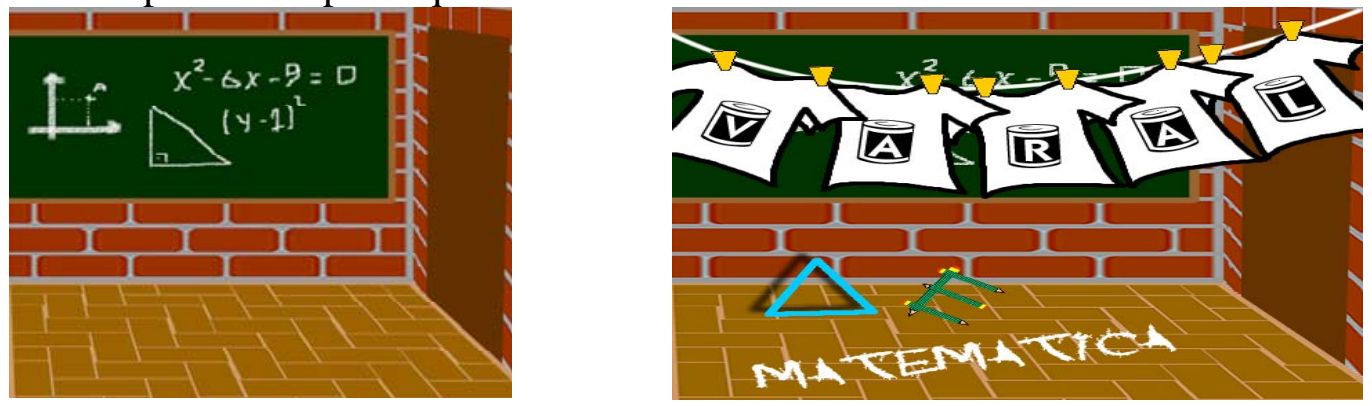

Figura 1 - Apresentação inicial do vídeo com a apresentação do evento com animação

Todo o trabalho foi realizado extra-classe pelos estudantes, onde suas dúvidas foram resolvidas via $M S N$ ou pelos corredores da escola. A figura 1 é um recorte da apresentação que foi construída no CorelDraw, e o vídeo encontra-se disponível em duas versões: Vídeo Spin (Pinnacle), e atualmente em Power Point (Microsoft), que demonstra a efetiva apropriação tecnologia dos estudantes e o estabelecimento de relações com os conteúdos de Geometria Plana e Espacial desenvolvidos no primeiro trimestre de 2009.

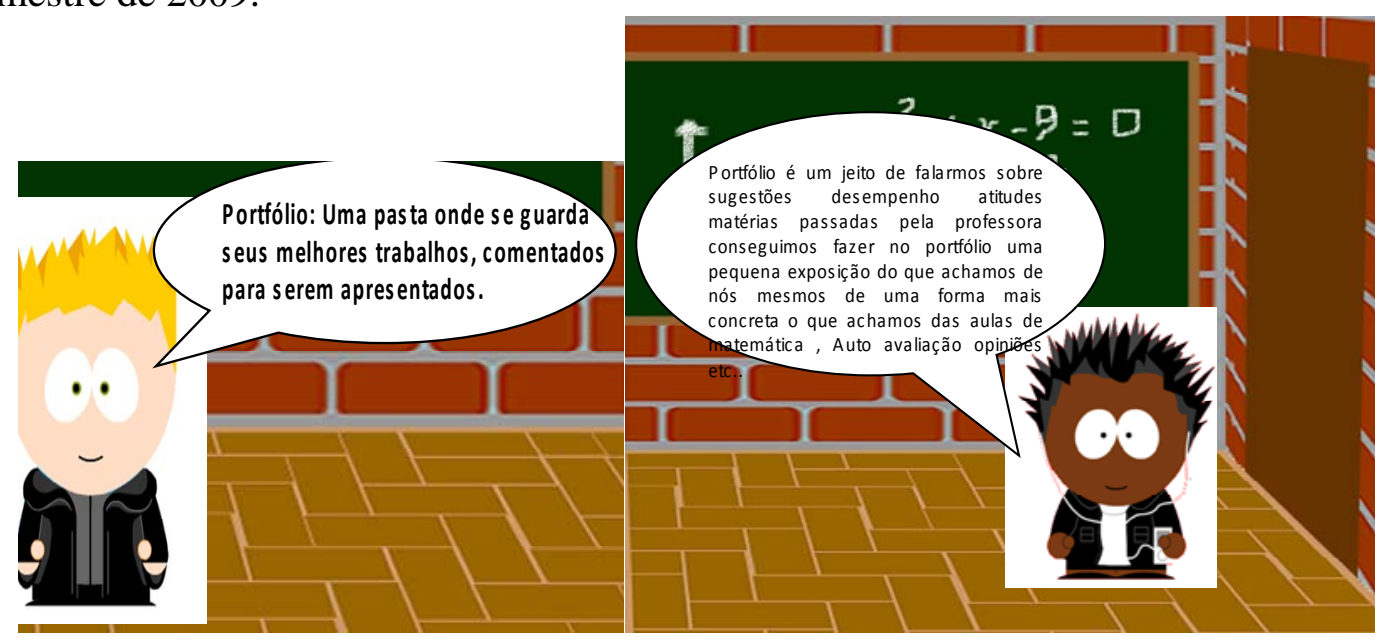

Figura 2 - Conceito de Portfólio de Matemática feito pelos estudantes.

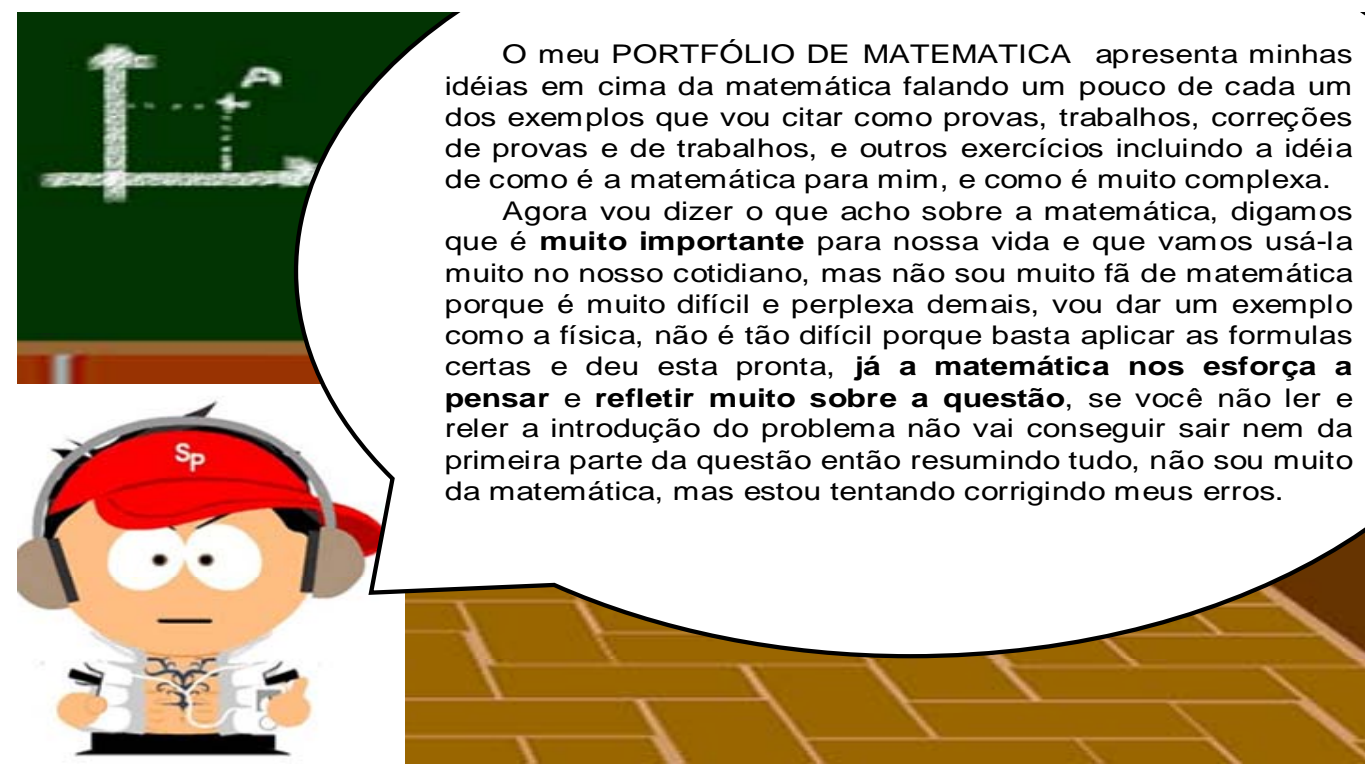

Figura 3 - Explicação do estudante sobre o que entende ser o portfólio de matemática. 


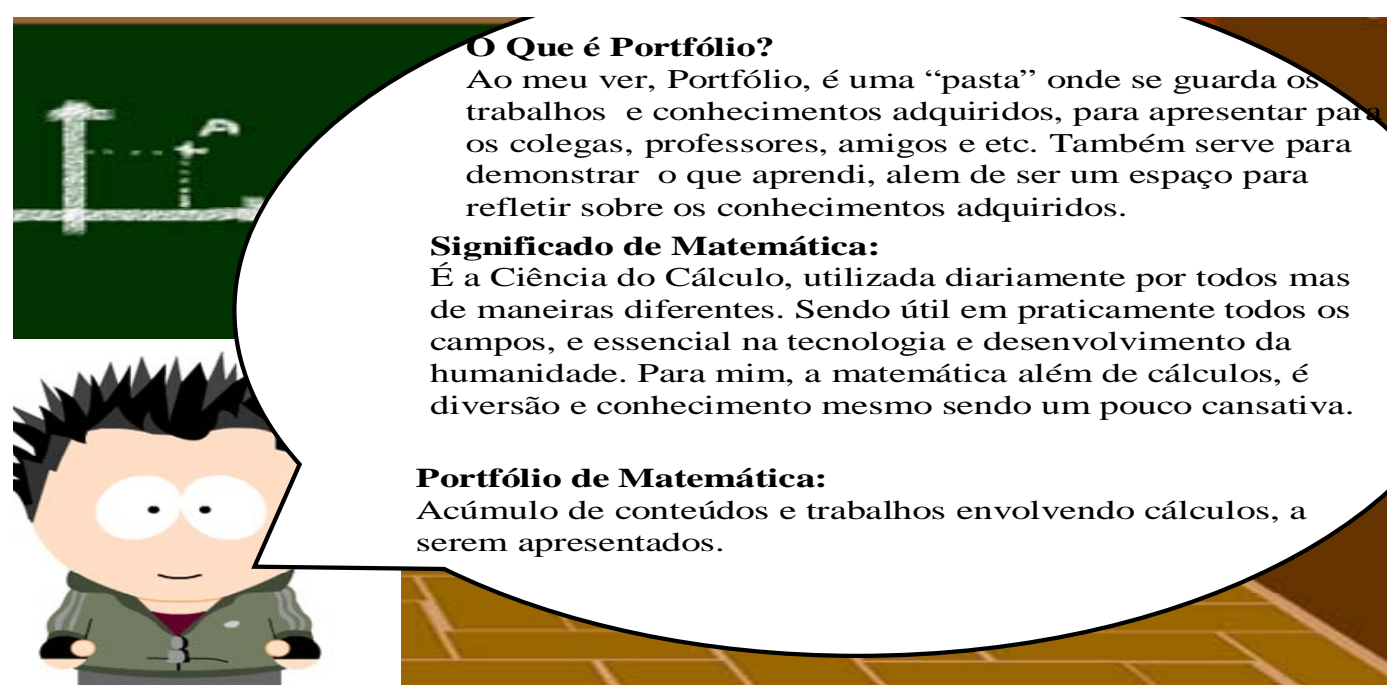

Figura 4 - Outra explicação sobre o que entende ser portfólio de matemática.

As figuras 2, 3 e 4 salientam a compreensão dos estudantes quanto à proposta dos portfólios além dos recursos tecnológicos por eles utilizados para criar suas imagens que demonstram a necessidade afetiva de se auto-avaliarem como agentes ativos e personalizados das suas opiniões. Salientamos que a professora que coordenou essas atividades não possui pleno domínio dos recursos tecnológicos e os estudantes se mostram dispostos a explicar e ensinar para a professora como construíram seus portfólios. Credita-se essa disposição dos estudantes ao fato de estar estabelecida uma "ótima” comunicação entre professora e estudantes e entre os próprios estudantes.

As figuras a seguir são questões escolhidas pelos estudantes e extraídas de seus portfólios do primeiro trimestre para fins de explicação. Essa escolha foi feita com base na opinião deles próprios: "questões simples, de interesse de todos e de fácil compreensão". Cada componente do grupo escolheu a sua e explicou segundo suas palavras apropriando-se dos símbolos matemáticos que julgou necessário para dar sua explicação. Destacamos novamente que toda a edição foi construída pelos estudantes e que tais slides são animados e com tempos sincronizados.

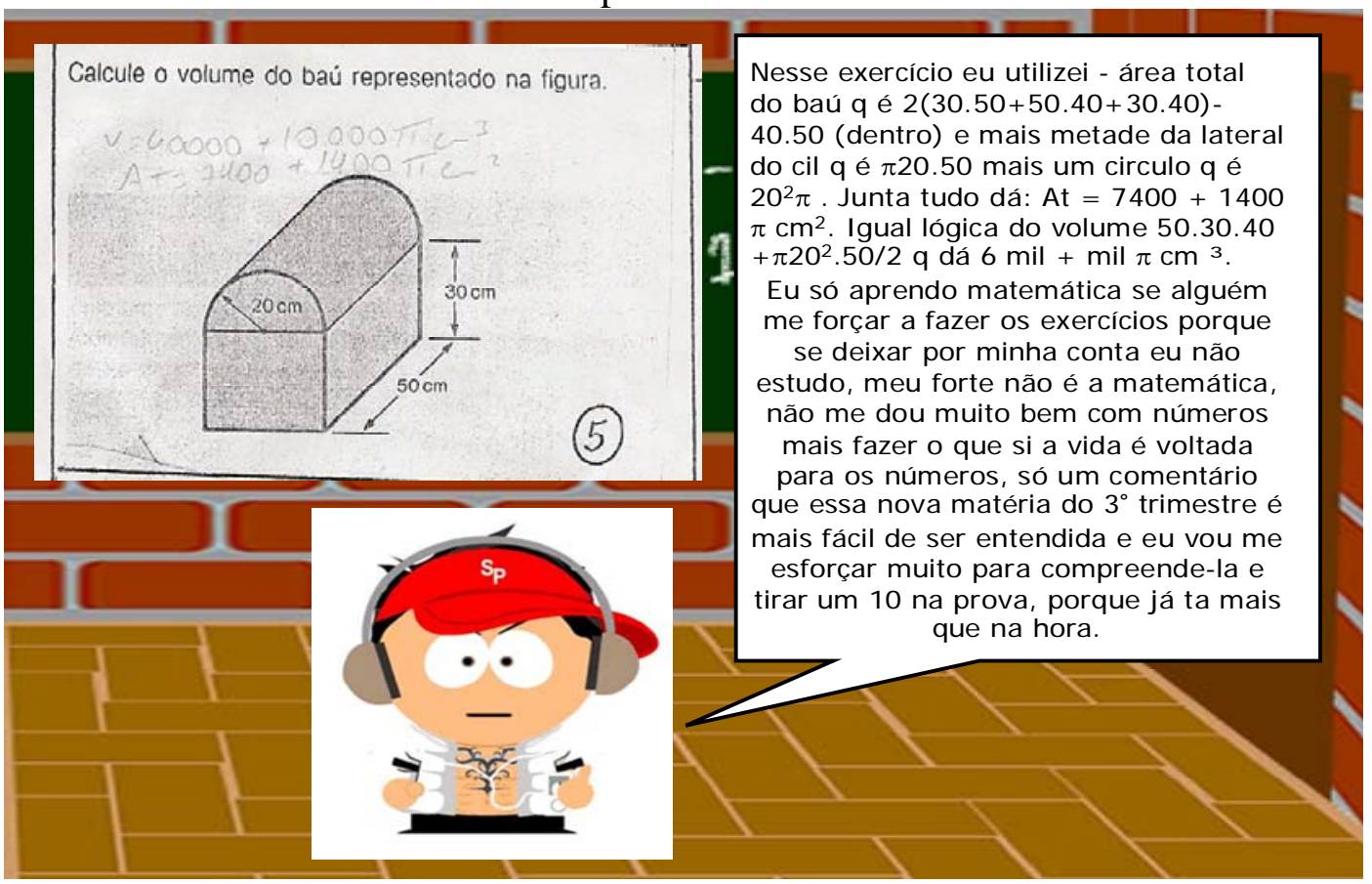

Figura 5 - Questão 5 da prova 1 do $1^{\circ}$ trimestre de 2009 sobre geometria espacial. 
Neste recorte observam-se aspectos cognitivos, metacognitivos e afetivos do estudante, pois ele demonstra saber resolver a questão, assim como escreve segundo sua compreensão, e explica como resolve, além de deixar "claro" sua auto-avaliação quanto aos conceitos de Matemática envolvidos. Segundo D`Ambrosio (1996), o importante é o estudante compreender matemática e fazê-la não importa como, desde que faça uso com significado, e Freire (1996) salienta que a busca pelo aprendizado é de responsabilidade do estudante assim como sua autonomia pela forma de aprendizagem e o quanto. Este estudante demonstra também a esperança de no $3^{\circ}$ trimestre recuperar suas notas. Observamos, no entanto, que esse estudante tem média para ser aprovado, mas se avalia como insuficiente segundo seu critério de exigência.

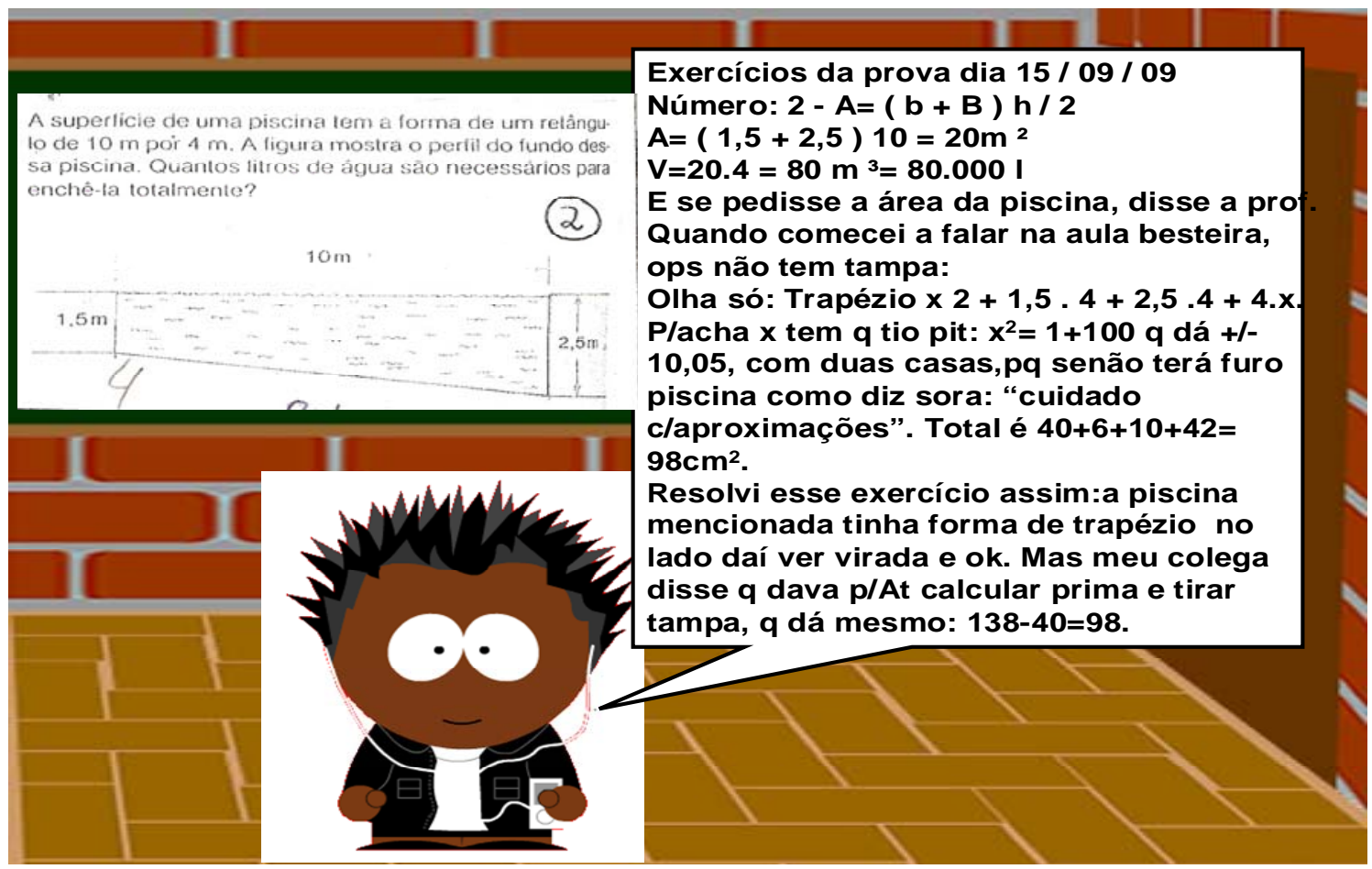

Figura 6 - O estudante além de escolher a questão ele demonstra que seu colega resolveu diferente.

O estudante escolheu uma questão bem recente da prova acumulativa de finalização de toda a geometria espacial, explicou com suas palavras destacando passagens de ideias com a professora e a diferente solução dada pelo seu colega na época, que no caso é o Ícone de cabelo amarelo do seu grupo. Assim, como o estudante anterior ele demonstra aspectos cognitivos, metacognitivos e afetivos, além de um cuidado/atenção com sua atitude em sala de aula. 


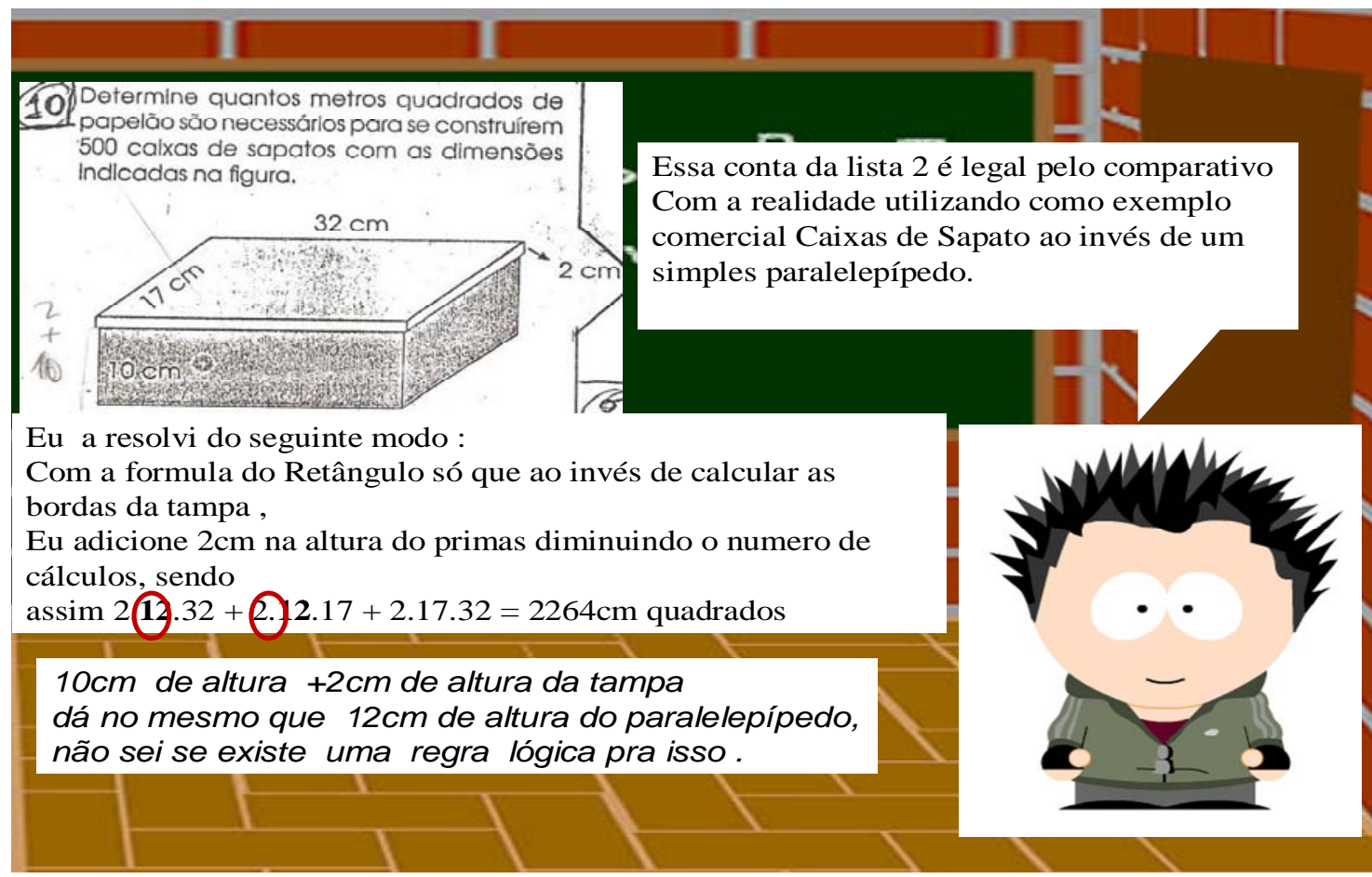

Figura 7 - Estudante contextualiza a questão com a sua realidade e faz relações aritméticas fascinantes para ele.

Ao ler este slide fica evidente uma simples associação da sua realidade com a sala de aula, porque esta caixa de papelão é de utilidade no comercio de calçados. Além disso, a relação aritmética por ele estabelecida quanto à tampa, segue uma regra lógica. Salientamos, na linha do que foi expresso por D`Ambrósio (1996), que brincar com a matemática é saudável e prazeroso, e segundo Freire (1999) aprender tem de ser "bom” e "alegre".

Outro aspecto interessante além do cognitivo, metacognitivo e afetivo evidenciado pelo estudante é a linguagem: "metros quadrados", porque quando questionado pela professora de porque não ter usado o "sobrescrito", o estudante disse: "estou escrevendo como faz a conta, daí é mais “reto" manter escrito”. E os sinais de mais? Ele disse que é de conhecimento de todos, daí todos os pais sabem o que significa. Ressalvamos a preocupação do estudante de que todos os visitantes compreendessem a sua apresentação e também a sua ideia do que as "pessoas sabem" de matemática, porque ele julga que os pais não conhecem a notação “ $\mathrm{m}^{2}$ ”. Segundo Freire (1996), na escola o estudante deve aprender a ler o mundo segundo seus olhos de reflexão e criticidade, assim formando-se um cidadão ativo da sociedade em que vive. 


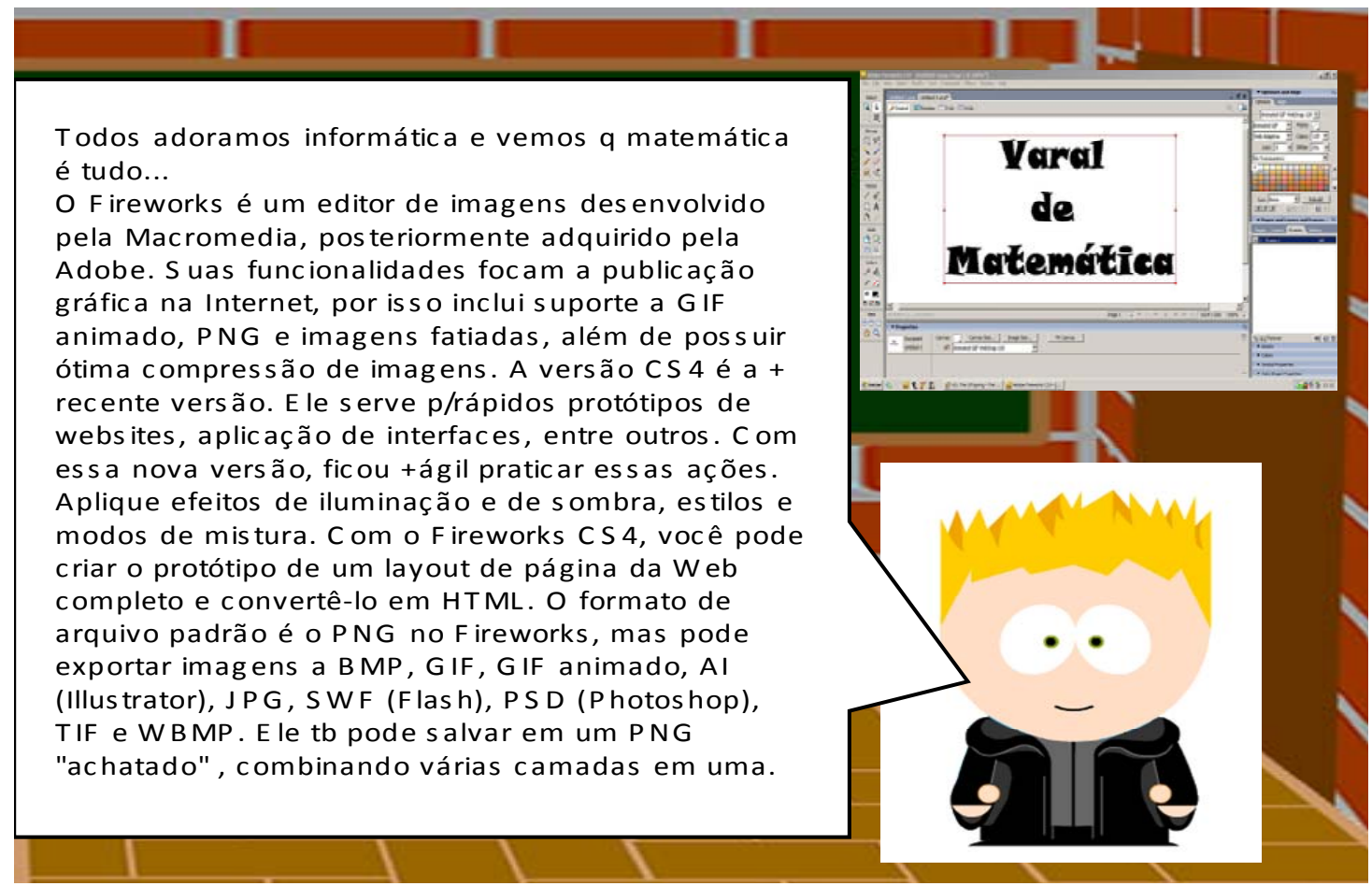

Figura 8 - O estudante associa a matemática a tudo de tecnologia.

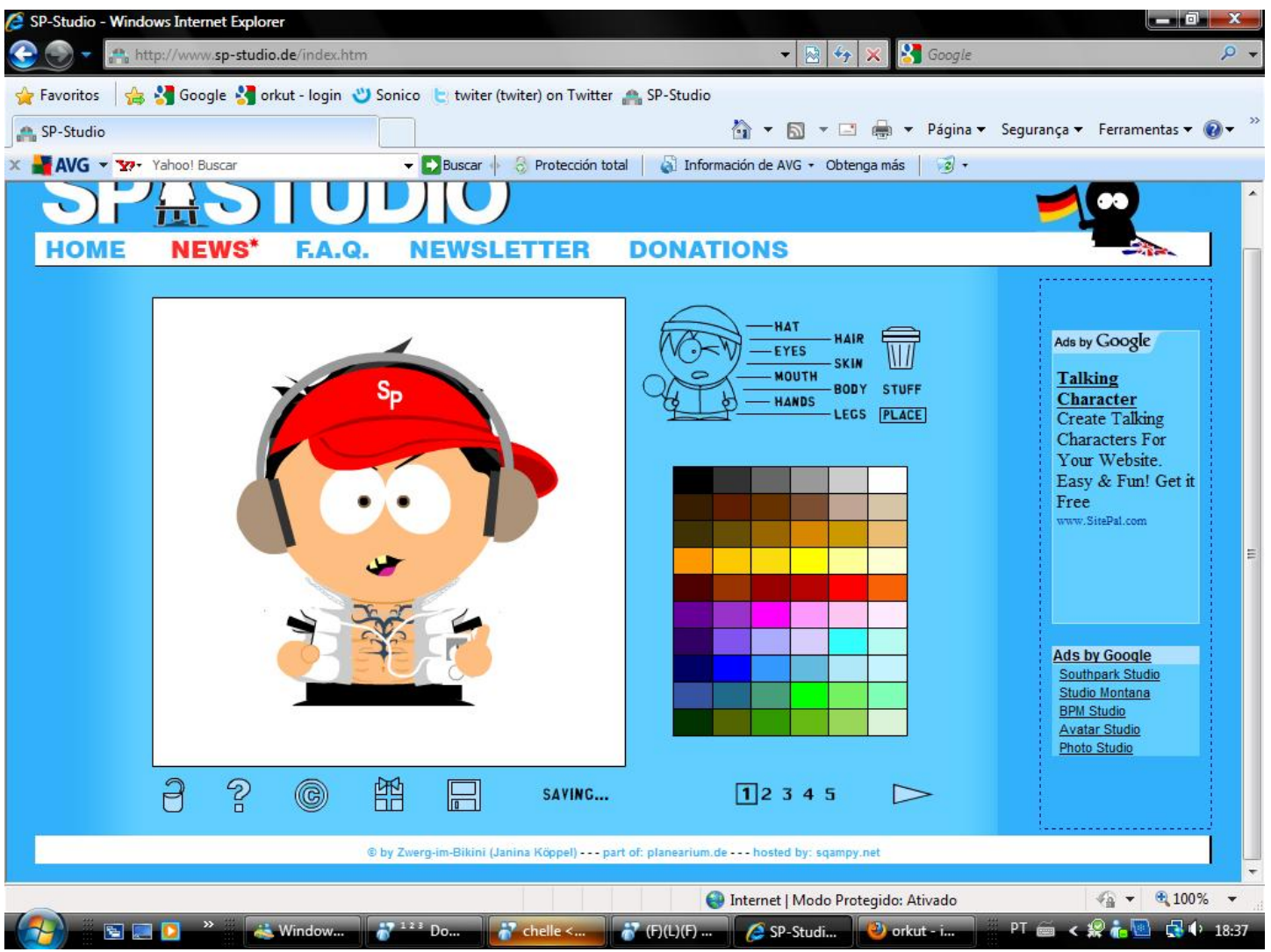

Figura 9 - Construção do Trabalho do Varal: janelas de edição de imagem, msn, ...

A apresentação deste estudante é bem grande e de certa complexidade, pois cita conceitos de proporcionalidade na construção das imagens de seus colegas como formas espaciais, tanto regulares como irregulares; ele demonstra um domínio significativo dos recursos tecnológicos assim como aplica os conceitos aprendidos de matemática com destreza e certa “lógica” como ele mesmo se refere em sua fala: “isso é lógico”. Além 
disso, citamos a palavra "achatado" e outras que destacam a sua naturalidade em relacionar os conceitos de matemática a realidade e seu uso nos programas de edição de imagens. A figura 9 é um exemplo do que foi solicitado ao estudante pela professorapesquisadora numa conversa pelo msn. Nesse diálogo via chat/msn, ele enviou um Print Screen da tela que visualizava quando disse que estava construindo o trabalho para apresentar os portfólios de matemática ao varal. Nesta imagem há mais uma evidência de que os estudantes atualmente fazem muitas coisas ao mesmo tempo, ou, como eles próprios se denominam, são os próprios hipertextos. Desta forma a aula deve ser diversificada se o professor deseja potencializar o desenvolvimento em sala de aula, como um espaço atrativo ao estudante.

Por fim, o último recorte do vídeo é um exemplo de união e reflexão coletiva sobre o próprio processo de aprendizagem de Matemática e seu papel na sociedade como agentes ativos e cidadãos críticos, segundo as ideias de Freire (1996), e a visualização de muitas possibilidades para o futuro, e que segundo Basso (2003), que o professor deve oportunizar espaços aos estudantes aprender a aprender.

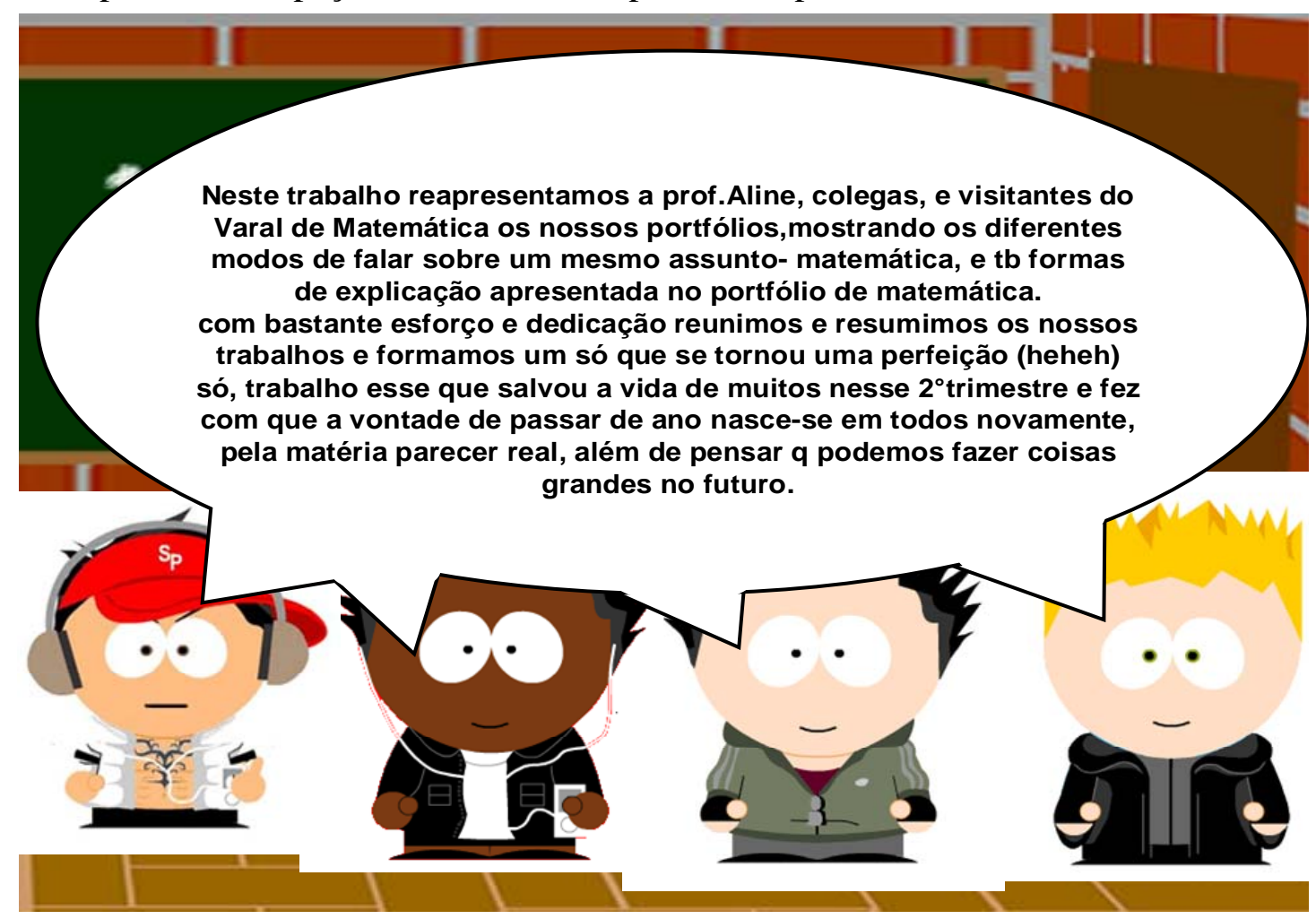

Figura 10 - Conclusão da apresentação sobre os portfólios de matemática.

\section{Certezas Provisórias}

Cada vez mais estamos rodeados de informações e tudo ao nosso redor move-se de uma forma instantânea possibilitando a cada ser humano ser o que desejar e se transformar a cada instante conforme o desenvolvimento de seu amadurecimento. Assim, o professor de Matemática que desejar manter-se "falando" com os estudantes deve adotar uma prática educativa que lhe permita aprender com os estudantes, aceitando e incorporando os recursos oferecidos pelas tecnologias digitais. Esta "fala” deve ser estimulada pelo professor para que o estudante construa o seu processo de aprendizagem de forma responsável e autônoma. 
Os aspectos cognitivos, metacognitivos, afetivos e tecnológicos são evidentes em $97 \%$ dos portfólios de matemática, dados esse comprovado pelos trabalhos apresentados pelos estudantes que fizeram parte dessa pesquisa, além de uma "alegria” visivelmente estampada no rosto dos estudantes quanto ao seu progresso em Matemática. Assim, o portfólio de matemática é um instrumento que proporciona ao professor avaliar e compreender o processo de aprendizagem dos estudantes, e aos estudantes é uma forma de demonstrar sua aprendizagem de matemática segundo suas palavras e de maneira que eles se auto-avaliem periodicamente a partir dos novos saberes aprendidos, compreendidos e apreendidos.

Enfim, os conteúdos de matemática são uma necessidade para compreender, por exemplo, como um editor de imagem funciona. Dessa forma, se constituem em uma necessidade ao estudante, sendo compreendidos de forma contextualizada e interdisciplinar aos olhos desse próprio estudante. Com isso, a avaliação de matemática dos estudantes é satisfatória tanto para a aprovação quanto para a sua vida, enquanto que o professor além de aprender sente-se realizado e satisfeito com seu trabalho ao ler os portfólios de matemática.

\section{REFERÊNCIAS}

BASSO, M.V.A. Espaços de aprendizagem em rede: novas orientações na formação de professores de matemática. Tese (doutorado). UFRGS - Programa de Pós-Graduação em Informática na Educação. Porto Alegre: UFRGS, 2003.

BASSO, M.V.A. Palestra Matemática na Escola: Experiências e Perspectivas. Mesa Redonda Ciência - Formação aos professores da Rede Municipal de Ensino de Porto Alegre. <http://euler.mat.ufrgs.br/ mbasso/expmat_SMED2009.pdf> Acesso online em 28 de dezembro de 2009.

BONA, A. S; BASSO, M.V.A. Portfólio de Matemática: um instrumento de análise do processo de aprendizagem. In: RENOTE - Revista Novas Tecnologias na Educação. XIV Ciclo de Palestras Novas Tecnologias na Educação. Vol. 7 N 2. Dezembro 2009. Disponível em: http://www.cinted.ufrgs.br/renote/dez2009/artigos/10a_alinesilva.pdf. Acesso online em 6 de janeiro de 2010.

D’AMBROSIO, U. Educação Matemática: da teoria à praxis. Campinas, SP: Papirus, 1996.(Coleção Perspectivas em Educação Matemática).

FREIRE, P. Educação com Prática de Liberdade. 23a ed. São Paulo: Paz e Terra, 1999. FREIRE, P. Pedagogia da Autonomia: saberes necessários à prática educativa. São Paulo: Paz e Terra, 1996.

LAFORTUNE, L., SAINT-PIERRE, L., A afetividade e a metacognição na sala de aula. Lisboa: Instituto Piaget, 1996.

LÉVY, P. As Tecnologias da Inteligência - O futuro do pensamento na era da informática. 13ª ed. São Paulo: Editora 34, 2004.

PERRENOUD, Philippe. Avaliação: da excelência à regulação das aprendizagens entre duas lógicas. Trad. Patrícia Chittoni Ramos. Porto Alegre: Artmed, 1999. 